\title{
Enhancing Sustainable Development through Web Based 3D Smart City Model Using GIS and BIM. Case Study: Sheikh Hamad City
}

\author{
Maher A. El-Hallaq1, Abdelkhalek I. Alastal'2, Raed A. Salha² \\ ${ }^{1}$ Civil Engineering Department, Engineering College, Islamic University of Gaza, Gaza, Palestine \\ ${ }^{2}$ Geography and GIS Department, Arts College, Islamic University of Gaza, Gaza, Palestine \\ Email: mhallaq@iugaza.edu.ps, abdelkhalek.alastal@gmail.com, msalha@iugaza.edu.ps
}

How to cite this paper: El-Hallaq, M.A., Alastal, A.I. and Salha, R.A. (2019) Enhancing Sustainable Development through Web Based 3D Smart City Model Using GIS and BIM. Case Study: Sheikh Hamad City. Journal of Geographic Information System, 11, 321-330.

https://doi.org/10.4236/jgis.2019.113019

Received: May 8, 2019

Accepted: June 15, 2019

Published: June 18, 2019

Copyright $\odot 2019$ by author(s) and Scientific Research Publishing Inc. This work is licensed under the Creative Commons Attribution International License (CC BY 4.0).

http://creativecommons.org/licenses/by/4.0/

(c) (i) Open Access

\begin{abstract}
Smart sustainable city is that uses the technology to transform their core systems and optimize the exploitation of limited resources; it is a knowledge-based system that provides real-time insights to stakeholders. As a result of the challenges facing the cities of the Gaza Strip regarding population growth, lack of resources, increased demand for materials, the siege imposed on the Gaza Strip for more than twelve years, the smart city approach can contribute to mitigating these challenges and creating opportunities and solutions for many of these problems. Thus, this study aims to promote sustainable urban development through the adoption of smart city approaches using the city's 3D representation and analysis capabilities to reflect and define the current situation and formulate a future vision using GIS and Building Information Modeling (BIM) considering Sheikh Hamad city as a case study. This involves developing a GIS web-based 3D model of the urban landscape of the city and creating a geometric descriptive database that includes the various elements of the city such as buildings, services and other facilities. The constructed database is to be automatically updated and can be used to facilitate documentation, transparency and help in decision-making process. The 3D smart city can also benefit stakeholders, government officials, private sectors as well as the city citizens. Therefore, urban services will be more efficient, and the cities of the Gaza Strip will be able to achieve sustainable development and competition in difficult economic, environmental and social conditions. This study recommends the use of BIM and GIS technologies in the transformation to a smart city concept as well as the rehabilitation of existing cadres to enable them to use those technologies to achieve the goal of improving the quality of life and facilitating the daily lives of people.
\end{abstract}




\section{Keywords}

BIM, GIS, Sheikh Hamad City, Smart City, Web 3D City Model

\section{Introduction}

The smart city is characterized using advanced technology on a large scale and the overall improvement of urban life sustainability, which requires huge and multi-source data for the use of technology and management. Urban services will therefore be more efficient, and cities will be more competitive in their social, economic, environmental and cultural conditions [1]. The features and possibilities offered by GIS and BIM technologies make it used widely in the construction industry, and to achieve maximum benefit through the integration of the diverse possibilities of these technologies [2]. This means that GIS and BIM data play an important and decisive role in smart and sustainable cities at all stages. The BIM model is a record of accurate, updated and detailed graphical and descriptive data for all building elements. This data is of utmost importance to all stakeholders from the designer, the owner, the final consumer, and the support of the decision maker. It also serves the various local organizations responsible for granting permits, providing services and assessing irregularities [3]. For GIS systems, data relating to a given building are directly related to its actual location on the city or region map. For example, a building site can be viewed in the context of other buildings in a neighborhood, its surface areas can be calculated, distances can be calculated for precise services, and satellite image data can be included in GIS systems to provide better visibility. Ubiquitously, accurate and comprehensive spatial data play a critical role in all areas of environmental management and sustainable development.

In order to control the full-cycle of construction effectively, technology of GIS and BIM can be useful because GIS and BIM can handle graphical and non-graphical documents, which make it easier to collect construction project information in a central database. Moreover, it can improve and speed up construction planning as well as ensure data integrity and accuracy. By integrating both GIS and BIM technologies, they can bring spatial analysis in a real-world spatial reference [4]. Shahi [5] emphasizes that the integration of BIM with GIS, will allow evaluation of a construction project in its urban context, allowing many intelligent urban management applications. Alastal et al. [6] aim to promote sustainable urban development by adopting the smart city approach by identifying the concept of smart cities in the reality of the cities of Gaza Strip, considering Khan Younis city as a case study. The study reveals that Khan Younis has $41.7 \%$ of the characteristics features of the smart city and needs further improvements in all axes especially the availability of social and economic infrastructures.

Song et al. [1] review the applications and future trends of BIM-GIS integra- 
tion in the architecture, engineering and construction (AEC) industry based on the studies of 96 high-quality research articles from a spatio-temporal statistical perspective. Results show that the utilization of BIM-GIS integration in the AEC industry requires systematic theories beyond integration technologies and deep applications of mathematical modeling methods, including spatio-temporal statistical modeling in GIS and BIM simulation and management. Al-Saggaf and Jrade [2] describe the methodology used in developing a model that integrates BIM and GIS to facilitate demolition waste management and control for megaprojects. The suggested BIM-GIS model can contribute to more green and efficient construction management. Khan and Adnan [7] evaluate two web-based GIS applications Google Maps and MapQuest to find out usability problems. Special criteria are adopted for usability evaluation of these two web-based GIS applications. Usability tests have been performed with six graduate users and questionnaires are filled out by these users. Interviews are also conducted with six users to validate the results. Zhang et al. [8] show that data integration is important for effective asset management. Many IT tools such as GIS and BIM are highlighted to facilitate such process in this study. Geospatial analysis is one of the main contributions of GIS for large scale asset management however 3D tools need to be further developed in order to achieve its big potential. Besides acting as a data pool, more benefits of BIM for asset management are still to be clarified.

\section{The 3D City Concept}

It is currently observed that cities are undergoing a transition and continuous development, in order to adapt with the rapid demographic, economic, social and environmental changes. By understanding the need for adaptation as an opportunity to develop the city towards greater sustainability and flexibility, most modern cities are trying to introduce innovative tools and methods to involve as many relevant players as possible in planning processes. In this context, 3D city models play an important role as promising techniques for building common understanding among all actors in different areas. In addition, these models include GIS functions with high data representation and analysis capabilities, opening more possible areas of application for public administration and decision support as well as citizen participation. Thus, 3D city models are an integral part of efforts to transform the traditional city into a smart city through information and communication technologies [9].

The 3D city plays an important role in transforming the smart city into the level of technologies and applications used and the development required for the knowledge infrastructure, in order to maximize the benefit to the residents of the city. The 3D city model is a digital representation of the earth's surface and related objects such as construction, trees, vegetation, and some man-made characteristics in urban areas. Demand for 3D city modeling is rapidly increasing in various applications [10]. GIS visualization techniques and 3D modeling of 
building information are applied not only to the region in its current state, but also to the simulation of future scenarios for sustainable and innovative development. Web-based applications are being developed and used to allow clear presentation of new urban development projects and scenarios, and to facilitate citizen participation in the planning and decision-making process. The most important goals and benefits of the 3D city models are [11]:

- It has a great role in quality control, continuity, management and service delivery.

- Through the 3D scenario of the current situation, sustainable and innovative scenarios can be developed, based on the current city data, current plans.

- It assists to map the environmental impacts, and energy mobility data by combining standard model outputs with the 3D GIS database.

- It facilitates to create an interactive 3D portal based on GIS for citizen participation and a decision support panel within the city government so that planners and decision-makers in the city have tools that allow for clear presentation of new projects and scenarios for urban development and allows citizens also to participate.

The 3D city models face a real challenge in three main levels. The first level of challenges relates to intelligent technologies that are essential to implement smart initiatives and projects. The second level of challenges is for intelligent users who will be smart city developers. The third level of challenges relates to the institutional dimension, smart management. The basic requirements for any city to transform to a 3D smart city should involve:

- Data availability in terms of accessibility, quality, and accuracy,

- Availability of qualified technical staff that can convert data in various forms to 3D models,

- Hardware and software availability which are very essential to store, process, manage and output data,

- Availability of governmental willingness to implement such 3D models.

\section{The Case Study}

Gaza Strip faces real challenges regarding population growth, lack of resources, increased demand for materials, the siege imposed on it for more than twelve years. Thus, following the smart city approach can contribute to mitigate these challenges and create opportunities and solutions for many of these problems. Sheikh Hamad city is selected as a case study to enhance sustainable development of Gaza Strip cities through 3D smart city model using GIS and BIM. The reason to choose Sheikh Hamad as a case study is because that it is considered the most important recently housing project in terms of its urbanization in the Gaza Strip. Its scale and size are also suitable for such study. In addition to, the project is distinctive from traditional planning aspects and is in a government-owned area.

The residential project of Sheikh Hamad city is located in the liberated lands, 
Mohararat, under the influence of Khan Younis Municipality in the southern Gaza Strip, northeast of the city of Asdaa Media, Figure 1. The land is wholly owned by the Palestinian National Authority. The total area of the city is about $404,446 \mathrm{~m}^{2}$. The number of residential buildings in it is 172 , consisting of 3628 housing units. Beside the residential buildings, it also includes schools, kindergartens, mosques, health center, women's activity center, cultural and social sports club, administrative building, civil defense building, police station and green areas. The city is served with network of main roads, aggregated and local, which has an area of $96,824 \mathrm{~m}^{2}$ with an occupancy rate of $23.9 \%$ [12].

\section{Methods and Results}

With the help of dedicated geoprocessing tools, the provided datasets are imported into the GIS environment. To develop a 3D BIM/GIS model, all geospatial and non-spatial datasets must be processed and homogenized in a geodatabase. With technical 3D modelling technology applied with ArcGIS tools, an almost fully automated modelling process is developed to create 3D visualization. Finally, a public web-based BIM/GIS application tool is published at ArcGIS platform in order to allow stakeholders and citizens to get access and benefit from this application. The 3D visualization of the city development scenario also helps citizens to better understand the terminology used in the urban planning process.

Figure 2 illustrates the methodology framework of this study. The most relevant stages of the processing workflows are discussed below.

\subsection{Data Acquisition and Processing}

Data availability is a fundamental prerequisite in order to accomplish this stage. High quality data needed in this stage should involve survey data, BIM data, road network, public utilities, green spaces, trees as well as high resolution orthoimages. As part of the data preparation, all datasets of the City should be

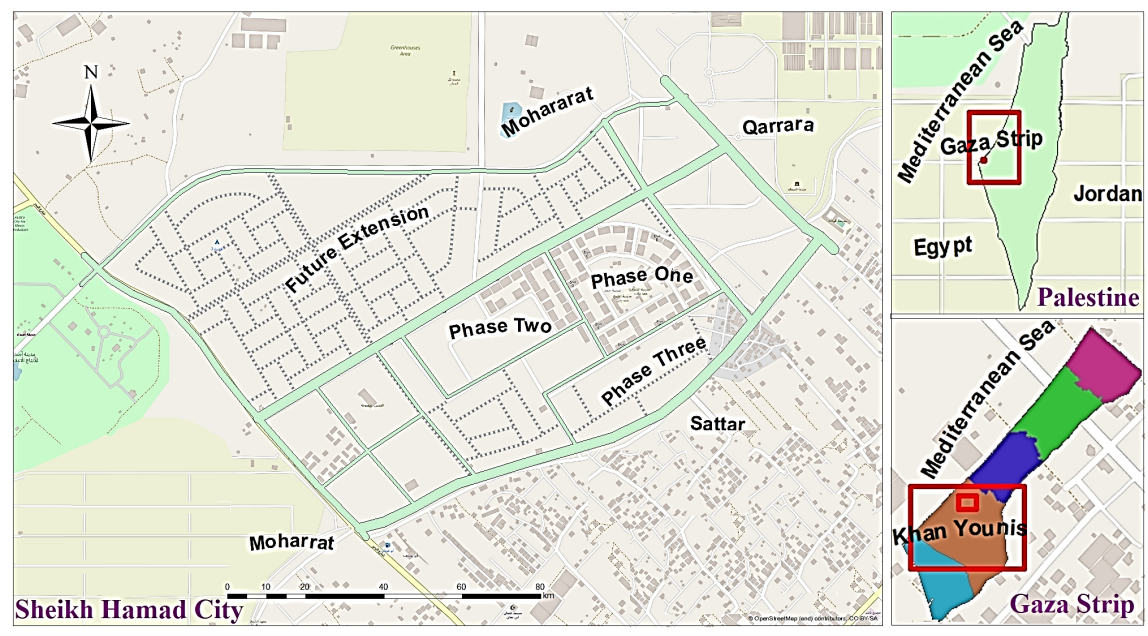

Figure 1. The geographic location of Sheikh Hamad city. 


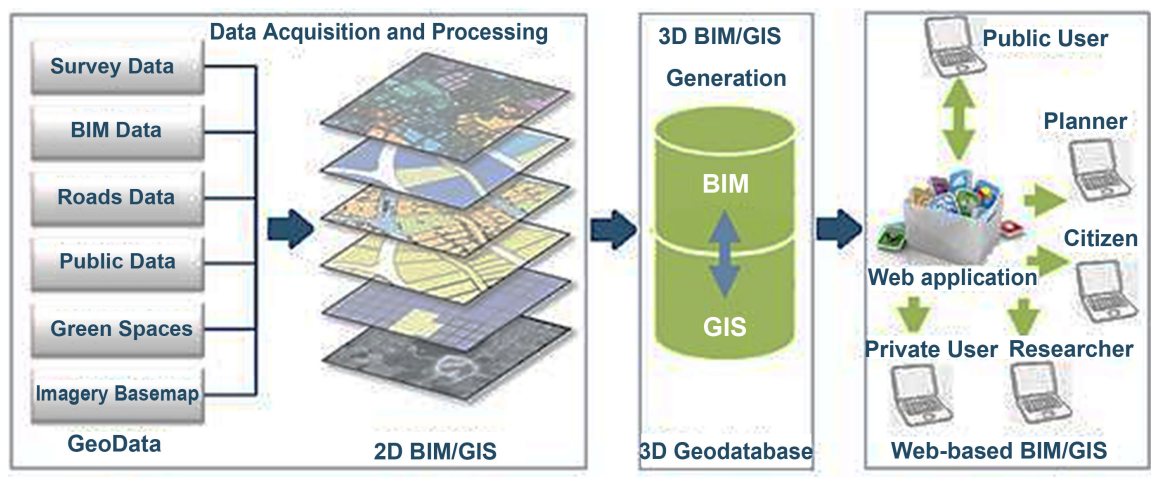

Figure 2. The methodology framework.

processed and georeferenced before they can be integrated and migrated into the GIS environment using GIS geoprocessing tools. In addition, attribute data for each dataset is tabulated with a high level of detail. As a result, a comprehensive geodatabase can be designed including all the necessary and processed datasets as a starting point for modeling the $3 \mathrm{D}$ visualization.

\subsubsection{BIM/GIS Generation}

ArcGIS pro v2.2.1 is used to handle 3D data by creating a Global Scene page. For buildings layer, 2D data is transformed to 3D by adding the height of residential buildings and the number of floors for each residential tower. 3D building models and its corresponded data are exported to Google Sketchup with Collada extension multipatch using the ArcGIS Toolbox. Then, the Collada file is opened using the Google Sketchup 2018 software to cover the building models with the facades and pictures to look as a real representation. After the facade of buildings are processed, files are exported back to Collada through Google Sketchup. To share the $3 \mathrm{D}$ data on the web, 3D layers must be processed and converted to a scene package. Similarly, the rest of other layers of the city such as water, wastewater, roads, electrical and other networks are processed with the same steps. Figure 3 shows the implementation workflow of the 3D BIM/GIS model development.

\subsection{Web-Based Application}

Active involvement of the citizens and other interested groups to share and benefit from the City data is a fundamental necessity. The web application (Figure 4) also allows getting online access to the planning documents anytime and anywhere and enables the citizens to state their position by providing their feedback. The 3D visualization of the status and the development scenario helps citizens to better understand the terminology of the planning statutes. The City data is uploaded to the ArcGIS portal/online server. All layers and attribute tables are added to the ArcGIS portal's 3D web browser with the properties of each layer. Figure 4 shows the basic interface of this web application.

The web application allows the user to select a suitable base map from a listed menu, view and navigate through the City scene from different looking directions 


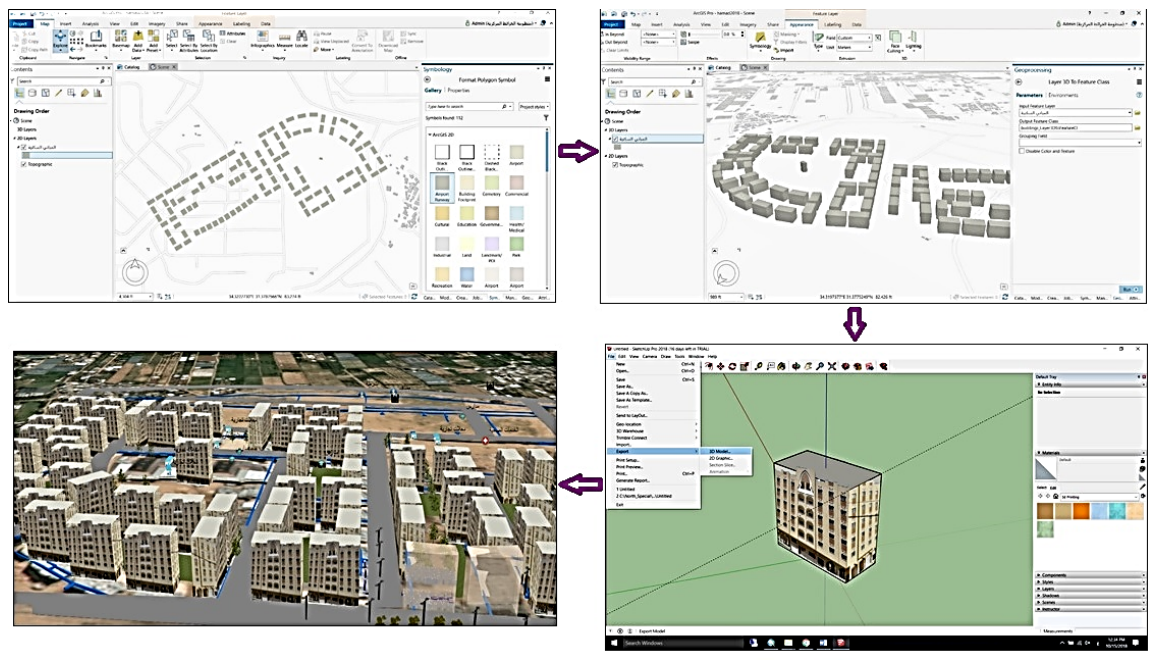

Figure 3. The workflow development of 3D BIM/GIS model.

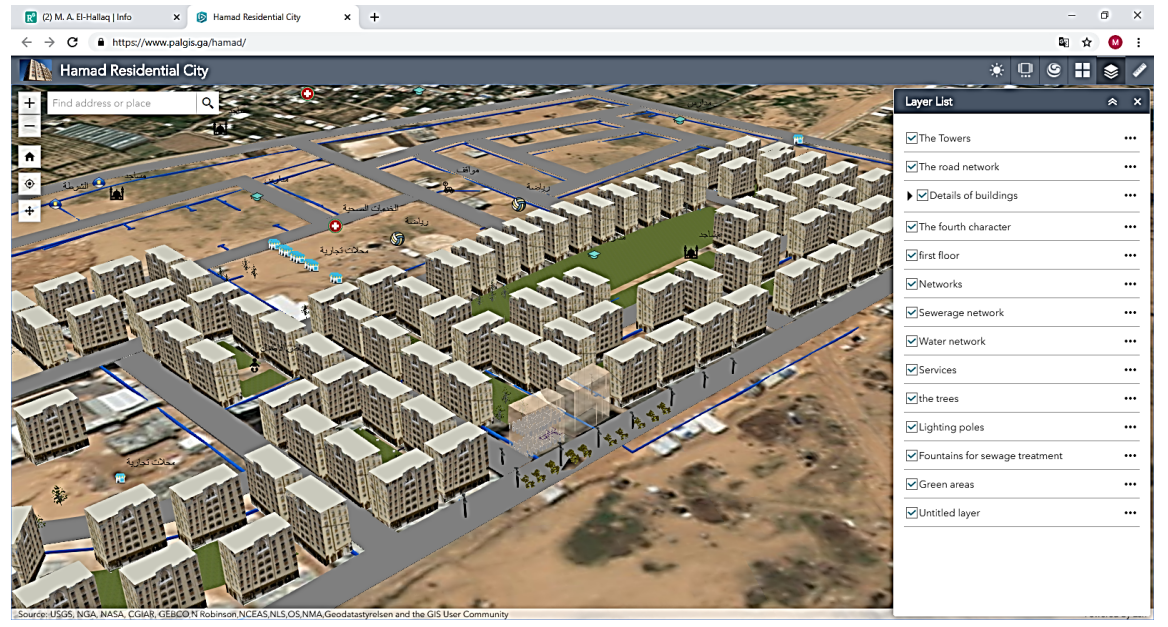

Figure 4. The main interface of the developed web model.

and consequently imagining and simulating the actual representation of the City. Moreover, it has the ability to perform various queries about the City facilities such as building information, roads inventory, electrical and water utilities characteristics with the possibility of updating this information automatically and periodically. It also can display the electrical, water and sewage networks inside apartments, search for the location of emergency units, in addition to illustrating the architecture distribution of rooms and other services.

The web site also offers measurement tools to compute distances between certain features or area of some objects under consideration. In addition, it provides some analytical tools for sun lighting which enable to monitor the change in shadows, to study lighting angles and their impact on residential towers and apartments throughout the year, to show its impacts on plantations and trees, in addition to the use of these analysis to arrange the well distribution of solar panels. Figure 5 illustrates some examples of the above-mentioned capabilities of the developed 3D web case study application. 


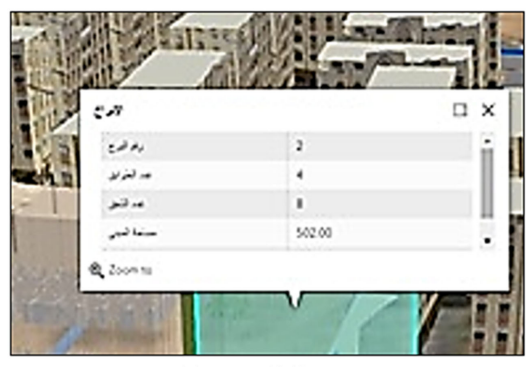

(a) Building Query

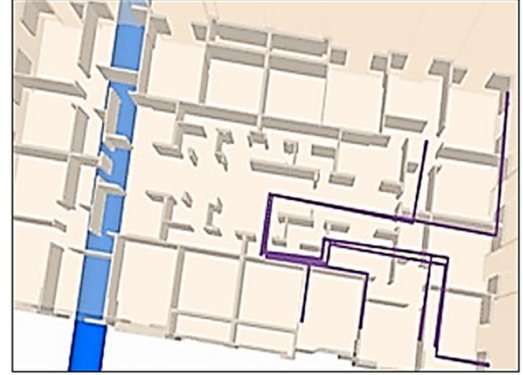

(c) Apartment Interior Utilities

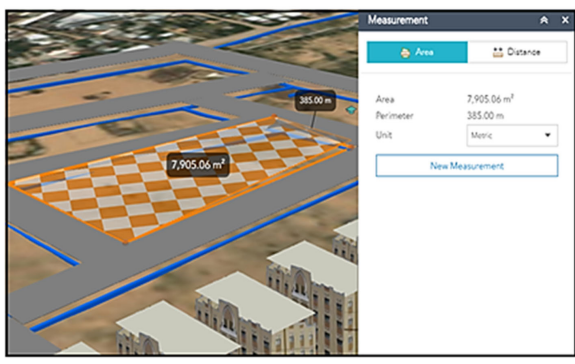

(b) Area Measurement

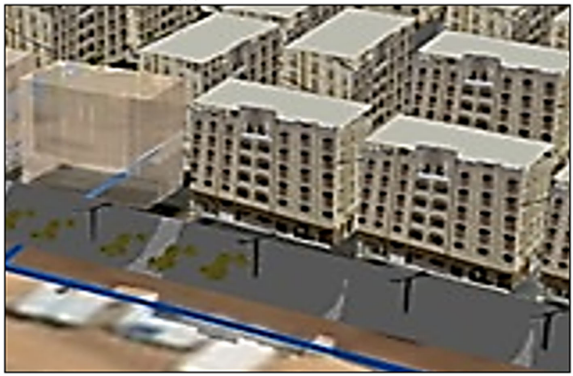

(d) Environmental Analysis

Figure 5. Examples of the 3D web interface capabilities.

\subsection{Case Study Discussion}

Based on this case study and its results, there is a great need to adopt a smart 3D city model in order to enhance sustainable urban development in the Palestinian cities, especially the cities of the Gaza Strip using BIM and GIS systems. Unfortunately, there are challenging problems encountered in the implementation process. These challenges are mainly due to unavailability of the City data; either insufficient level of data detail or difficulty of accessing because it is archived among various institutions. Other challenges are technical and input from the inability to implement GIS analysis, environmental impact mapping, and city data by combining standard model outputs with the 3D GIS database, as typical standard outputs are not available to compare with the existing database.

The developed web application gives helpful basic functions that can assist in:

- Research, exploration and display: Any information on 3D maps; residential buildings, utilities, services, water network, sanitation and other accessories can be queried and researched with the possibility of updating.

- Analysis and simulation: The analytical tools discussed in the case study allow to suggest more than one scenario and the best choice is taken before the project is launched on the ground. 3D model adds an additional dimension to the presentation and representation of data. It also contributes to the reduction of visually complex information to represent City components in order to better understand such complexity.

- E-collaboration: achieve cooperation between different working teams, facilitate communication, and sharing data between them, and thus save time and effort required to accomplish the tasks.

- Infrastructure and Facilities Management: As a result of the availability of an integrated central geographic database for all elements of the city, the infra- 
structure and facilities in the city can be managed efficiently and effectively in terms of follow-up, maintenance, delivery of services, greatly reducing resource waste and thus quality control to improve quality of life of the City citizens.

- Digitizing planning: To achieve comprehensiveness and avoid repetition.

- Provide planners and decision makers in the city tools to allow a clear presentation of projects and new scenarios for the development of city, and allows the participation of citizens, and promotion.

The expected benefits of implementing the city's 3D Smart City strategy in Sheikh Hamad case study help to build and manage a 3D geometric and descriptive database of the various elements city and allows stakeholders from governmental and private institutions, as well as citizens to provide them with a clear vision of effective policies, best practices and consequently support decision-making. It contributes to better management of infrastructure and facilities with a way of more efficiency, more effectiveness, and reduce waste of resources. The strategy also contributes to saving time, effort and resources, which are positively reflected on all processes and projects. Moreover, it improves the quality of services provided to citizens and thus contribute to improving the quality of life. It can also contribute to the development of sustainable and innovative future scenarios for this area and outline project requirements.

\section{Conclusion and Recommendations}

The Gaza Strip faces multiple problems of limited space, continuous population growth, and the depletion of already scarce natural resources. In addition, it subjects to a continuous siege and successive destructive wars. All these problems require proper planning and rational use of available resources. Thus, the integrated features and capabilities offered by BIM and GIS technologies make it an important and effective role in managing assets and resources with suitable efficiency and high quality, Urban services will therefore be more efficient and the cities of the Gaza Strip will be more able to achieve sustainable development and competition in difficult economic, environmental and social conditions. Therefore, urban services will be more efficient, and the cities of the Gaza Strip will be able to achieve sustainable development and adaption in difficult economic, environmental and social conditions. In this study, a 3D BIM/GIS model is developed for Sheikh Hamad city in the Gaza Strip as an example. In addition, a web-based application is launched to assist in sharing, viewing, managing, analyzing and supporting decision-making process. This study recommends the use of BIM and GIS technologies in the transformation to a smart city concept as well as the rehabilitation of existing cadres to enable them to use those technologies in order to achieve the goal of improving the quality of life and facilitating the daily lives of people.

\section{Conflicts of Interest}

The authors declare no conflicts of interest regarding the publication of this paper. 


\section{References}

[1] Song, Y., Wang, X., Yi, T., Wu, P., Sutrisna, M. and Cheng, J. (2017) Trends and Opportunities of BIM-GIS Integration in the Architecture, Engineering and Construction Industry: A Review from a Spatio-Temporal Statistical Perspective. International Journal of Geo-Information, 6, 397. https://doi.org/10.3390/ijgi6120397

[2] Al-Saggaf, A. and Jrade, A. (2015) Benefits of Integrating BIM and GIS in Construction Management and Control. 5th International Construction Specialty Conference of the Canadian Society for Civil Engineering (ICSC), 2015, Canada.

[3] Vanier, D.J. (2001) Why Industry Needs Asset Management Tools. Special Issue on Information Technology for Life-Cycle Infrastructure Management. Journal of Computers in Civil Engineering, 15, 35-43. https://doi.org/10.1061/(asce)0887-3801(2001)15:1(35)

[4] Abdul Basir, W., Majid, Z., Ujang, U. and Chong, A. (2018) Integration of GIS and BIM Techniques in Construction Project Management-A Review, The International Archives of the Photogrammetry, Remote Sensing and Spatial Information Sciences, Volume XLII-4/W9. International Conference on Geomatics and Geospatial Technology (GGT2018), 3-5 September 2018, Kuala Lumpur, Malaysia. https://doi.org/10.5194/isprs-archives-xlii-4-w9-307-2018

[5] Shahi, K. (2018) Evaluation of Current Construction Permitting Process in City of Toronto and Future of Permitting in the Global Construction Industry. Master Thesis, University of Toronto, Canada.

[6] Alastal, A.I., Salha, R.A. and El-Hallaq, M.A. (2019) The Reality of Gaza Strip Cities towards the Smart City's Concept. A Case Study: Khan Younis City. Current Urban Studies, 7, 143-155. https://doi.org/10.4236/cus.2019.71006

[7] Ali Khan, Z. and Adnan, M. (2010) Usability Evaluation of Web-Based GIS Applications-A Comparative Study of Google Maps and MapQuest. Master Thesis, Blekinge Institute of Technology, Sweden.

[8] Zhang, X., Arayici, Y., Wu, S., Abbott, C. and Aouad, G. (2009) Integrating BIM and GIS for large Scale (Building) Asset Management: A Critical Review. Paper for CC2009, School of the Built Environment, University of Salford, UK.

[9] Wendt, W. and Mauthner, J. (2015) Visualization of Vibrant Cities and Regions-Identification, Design and Development of 3D-GIS Applications and Modules. REAL CORP 2015-PLAN TOGETHER-RIGHT NOW-OVERALL_From Vision to Reality for Vibrant Cities and Regions. Proceedings of 20 th International Conference on Urban Planning, Regional Development and Information Society, 695-704.

[10] Jain, K., Singh, S. and Mandla, V. (2015) Virtual 3D City Modeling: Techniques and Applications. Conference: 3D GeoInfo, Istanbul, 27-29 November 2013, 73-91. DOI: 10.5194/isprsarchives-XL-2-W2-73-2013.

[11] Schaller, J., Ertac, O., Freller, S., Mattos, C. and Rajcevic, Z. (2009).Geodesign Apps and 3D Modeling with City Engine for the City of Tomorrow. In: Digital Landscape Architecture 2015-Landscape Architecture and Planning Proceedings, Anhalt University of Applied Sciences, Herbert Wichmann Verlag, VDE VERLAG GMBH, Berlin, 59-70.

http://gispoint.de/fileadmin/user_upload/paper_gis_open/DLA_2015/537555006.pdf

[12] Palestinian Central Bureau of Statistics PCBS (2017) Statistical Yearbook of Palestine, No. 18, Ramallah, Palestine. http://www.pcbs.gov.ps/Downloads/book2362.pdf 